\title{
Manajemen Mitigasi Bencana dengan Teknologi Informasi di Kabupaten Ciamis
}

\author{
Etika Emaliyawati, Ayu Prawesti, Iyus Yosep, Kusman Ibrahim \\ Fakultas Keperawatan Universitas Padjadjaran \\ Email:etika@unpad.ac.id
}

\begin{abstract}
Abstrak
Jawa Barat merupakan wilayah rentan kejadian bencana. Kabupaten Ciamis merupakan daerah yang mempunyai tingkat kerawanan cukup tinggi terhadap kejadian bencana alam tanah longsor dan banjir berdasarkan pemetaan secara global 2012-2029. Namun demikian, penanganan bencana belum tertangani secara optimal. Penanganan korban pada kondisi bencana belum tertangani dengan baik karena minimnya koordinasi, data layanan kesehatan yang tidak memadai sehingga menyebabkan tidak tertanganinya korban akibat bencana. Penggunaan sistem informasi dalam penanganan bencana sangat diperlukan khususnya untuk aspek layanan kesehatan. Tujuan penelitian ini terbentuknya sistem informasi kesehatan khususnya dalam penanganan bencana di Kabupaten Ciamis untuk memudahkan dalam koordinasi penanganan korban dimulai dari lokasi bencana, evakuasi dan transportasi korban ke tempat layanan kesehatan yang sangat tergantung dari kondisi korban, sarana dan prasarana fasilitas kesehatan, logistik yang dibutuhkan, jarak dan waktu tempuh ke tempat layanan kesehatan, serta sumber daya manusia di tempat layanan kesehatan. Penelitian menggunakan metode riset terapan, menggunakan sistem informasi geografis (SIG) dengan perangkat lunak arcgis. Hasil penelitian ini yaitu terbentuknya prototipe sistem informasi kesehatan di Kabupaten Ciamis yang diberi nama "Sistem Informasi Bencana Padjadjaran (SIMBARAN)" berisi elemen kesehatan yang diperlukan selama bencana meliputi layanan kesehatan terdekat di sekitar kejadian, sumber daya manusia yang tersedia, saranan prasarana, penanggung jawab program dan sistem rujukan sehingga memudahkan dalam koordinasi penanganan korban yang nantinya diharapkan dapat menurunkan angka kematian korban akibat bencana ataupun kejadian kecelakaan lainnya. Direkomendasikan agar setiap kabupaten di wilayah Jawa Barat memiliki model Sistem Informasi Bencana karena wilayah Jawa Barat yang rentan terhadap kejadian bencana.
\end{abstract}

Kata kunci: Aspek kesehatan, mitigasi, sistem informasi, "simbaran".

\section{Disaster Mitigation Management use Information Technology in Ciamis}

\begin{abstract}
West Java is one of region with susceptible disaster. Ciamis is an area that has a fairly high level of vulnerability to natural disasters as landslides and floods based mapping globally from 2012 to 2029. However, disaster management has not handled optimally. Handling of victims in the disaster condition is not handled properly due to lack of coordination, health services data is inadequate, causing no casualties from the disaster Settlement. Using of information systems in disaster management is indispensable, especially for health services aspects. The study purpose is establishment of health information systems, especially in disaster management in Ciamis to facilitate the coordination of the handling of victims starting from the disaster site, evacuation and transportation of victims to the health service that is highly depend on the condition of the victim, facilities and infrastructure of health facilities, logistics required, distance and time to the health service, and human resources in the health service. The research method applied research, using a geographic information system (GIS) software ArcGIS. The results of this study is the formation of a prototype health information system in Ciamis, named "Information System Disaster Padjadjaran (SIMBARAN)" contains the elements necessary health during disasters include the nearest health service in the vicinity of the incident, the human resources available, the proposition infrastructure, responsible program and a referral system to facilitate the coordination of the handling of victims who might be expected to decrease the death toll from the disaster or other accident scene. This study being recommended for each district in West Java has a Disaster Information System model because West Java region that is susceptible to disaster events.
\end{abstract}

Keywords: Information systems, health aspects, mitigation, "simbaran". 
Etika Emaliyawati: Manajemen Mitigasi Bencana dengan Teknologi Informasi

\section{Pendahuluan}

Indonesia adalahnegarayang rentanterjadinya bencana, hal ini dikarenakan kondisi geologi dimana perairan Indonesia sepanjang pantai bagian barat Sumatera, pantai selatan Jawa hingga perairan Nusa Tenggara, Papua dan Sulawesi terletak diantara lempenglempeng tektonik aktif diantaranya lempeng Eurasia, Indo Australia dan lempeng dasar Samudera Pasifik. Pergerakan lempenglempeng tektonik tersebut menyebabkan terbentuknya jalur gempa bumi, rangkaian gunung api aktif serta patahan patahan geologi yang merupakan zona rawan bencana gempa bumi dan tanah longsor (Haryadi P, 2007). Kabupaten Ciamis sebagai daerah yang mempunyai tingkat kerawanan cukup tinggi terhadap kejadian bencana alam (tanah longsor/pergerakan tahan dan banjir) berdasarkan pemetaan secara global yang telah dikaji dalam revisi RTRW No. 2 tahun 2012-2029. Namun demikian, penanganan bencana belum tertangani secara optimal. Atas dasar hal tersebut perlu penataan daerah rawan bencana guna penyusunan rencana yang terintegritas dari hulu sampai hilir dalam penanganan daerah rawan bencana sehingga dapat memberikan panduan/acuan kepada Pemerintah Kabupaten Ciamis agar mampu merencanakan penataan, memberikan arahan pemanfaatan dan penentuan pola ruang untuk kawasan-kawasan rawan bencana yang ada di Kabupaten Ciamis (Badan Penanggulangan Bencana Daerah Kabupaten Ciamis, 2010)

Penatalaksanaan penanganan korban bencana saat ini belum tertangani secara maksimal, dimana evakuasi korban bencana sangat sulit dilakukan dan seringkali menimbulkan keterlambatan penanganan (Murni, T.W, 2010). Hal ini terjadi selain kondisi infrastruktur yang rusak juga koordinasi dengan tempat layanan kesehatan terdekat masih sulit dilakukan, sumber daya manusia, dan fasilitas kesehatan yang tersedia tidak terinformasikan secara jelas, sehingga penanganan korban menjadi terlambat. Berdasarkan fenomena tersebut, maka masyarakat dan pemerintah daerah pun seharusnya sudah menyadari dan mewaspadai, dan siap siaga terhadap kemungkinankemungkinan buruk yang dapat terjadi akibat bencana di daerahnya. Salah satu upaya yang dapat dilakukan adalah upaya meningkatkan mitigasi bencana di daerahnya.Mitigasi yang cepat dan tepat ketika terjadi bencana terbukti dapat meminimalkan korban akibat bencana, baik korban jiwa, korban luka-luka maupun kerugian fisik dan material.

Salah satu teknologi dalam mitigasi bencana untuk mengurangi korban jiwa ataupun luka-luka adalah dengan mengaktifkan teknologi informasi dengan melibatkan sumber daya layanan kesehatan, baik sumber daya manusianya, sarana dan prasarana yang tersedia, dan kemudahan dalam mengakses layanan kesehatan tersebut. Data dan informasi mengenai sarana dan layanan kesehatan sangat dibutuhkan pada seluruh fase bencana, baik pada fase prabencana, tanggap darurat maupun paskabencana.Informasi tersebut dapat membantu dalam pengambilan keputusan yang cepat dan tepat pada saat penanganan korban bencana, untuk menyelamatkan korban cedera maupun mengurangi korban jiwa.

Menurut Badan Nasional Penanggulangan Bencana (BNPB), informasi sarana kesehatan yang dibutuhkan terdiri dari: instansi/lembaga pengelola, sumber daya manusia (SDM), sarana prasarana, logistik, dan peralatan (Wibowo, 2011). Dalam manajemen mitigasi bencana memerlukan kerjasama lintas sektoral dan melibatkan berbagai disiplin ilmu. Profesi keperawatan merupakan profesi yang anggotanya berjumlah besar, tersebar di berbagai wilayah dari mulai perkotaan, pedesaan dan dusun terpencil. Peran perawat ketika bencana yaitu sebagai agen pemberdayaan masyarakat dan atau pemberi bantuan kesehatan langsung baik pada tahap pra-bencana, bencana dan pasca-bencana. Perawat mempunyai kewajiban untuk melakukan intially assessment korban bencana, mengidentifikasi kebutuhan korban, memberikan pertolongan dalam upaya life saving, evakuasi korban sampai korban mendapatkan penanganan perawatan/kesehatan yang tepat (Persatuan Perawat Nasional Indonesia,2012; Putra. 2011). Dalam evakuasi korban perawat perlu melakukan rujukan ke fasilitas kesehatan, pemilihan layanan kesehatan hendaknya yang sesuai dengan kemampuan dalam penanganan korban. Selama ini hal tersebut tidak terinformasikan dan belum ada 
Etika Emaliyawati: Manajemen Mitigasi Bencana dengan Teknologi Informasi

sistem informasi kesehatan terpadu dalam menghadapi kondisi bencana.

\section{Metode Penelitian}

Metode penelitian yang digunakan adalah riset terapan. Penelitian dilakukan di wilayah Provinsi Jawa Barat khususnya Kabupaten Ciamis. Kegiatan dimulai dengan pengumpulan data bersama dengan Badan Penanggulangan Bencana Daerah dan Dinas Kesehatan Kabupaten Ciamis, ruang lingkup kegiatan meliputi sarana dan layanan kesehatan di wilayah Kabupaten Ciamis khususnya layanan kesehatan pemerintah meliputi rumah sakit dan puskesmaspuskesmas yang tersebar di Kabupaten Ciamis.

Pada penelitian ini dibuat sistem informasi kesehatan terkait bencana yang diberi nama "Sistem Informasi Bencana Padjadjaran (SIMBARAN)". Sistem ini menggunakan sistem informasi geografis atau biasa disingkat SIG merupakan salah satu tools atau alat yang banyak digunakan dalam proses pengelolaan informasi kebumian. SIG sebagai sistem komputer yang digunakan untuk memanipulasi data geografi. Sistem ini diimplementasikan dengan perangkat keras dan perangkat lunak komputer yang berfungsi untuk akusisi dan verifikasi data, kompilasi data, penyimpanan data, perubahan dan pembaharuan data, manajemen dan pertukaran data, manipulasi data, pemanggilan dan presentasi data serta analisa data (Bernhardsen, 2002; Cholid, 2009).

SIG bekerja dengan menggabungkan komponen-komponen kunci yang terdiri dari: a. Perangkat Keras (hardware)

Komponen perangkat keras (hardware) dalam SIG dikelompokkan berdasarkan fungsinya, yaitu :

1. Peralatan pemasukan data, seperti digitizer, scanner, keyboard, Global Positioning System (GPS), dan lain-lain.

2. Peralatan penyimpan dan pengolahan data, yaitu komputer dan perlengkapannya.

Peralatan untuk mencetak hasil, yaitu printer dan plotter.

\section{b. Perangkat Lunak (Software)}

Komponen perangkat lunak SIG mempunyai tugas menyediakan fungsi-fungsi dan alatalat yang diperlukan untuk menyimpan, menganalisis, dan memperagakan informasi geografis. Yang termasuk dalam komponenkomponen software adalah:

1. Alat untuk memasukkan \& memanipulasi informasi geografik

2. Data Base Management System (DBMS), yaitu sebuah database untuk sistem pengelolaan informasi geografis.

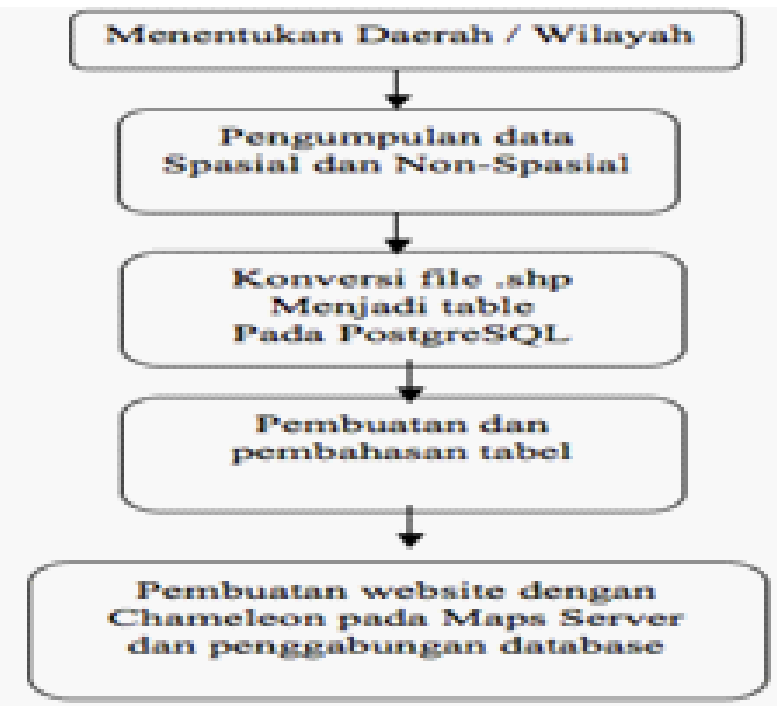

Gambar 1 Alur Penelitian 
Etika Emaliyawati: Manajemen Mitigasi Bencana dengan Teknologi Informasi

3. Alat untuk mendukung query, menganalis dan memvisualisasikan informasi geografis.

- GUI (Graphical User Interface) untuk mempermudah pengaksesan kepada tools yang ada dalam SIG.

\section{c. Data}

Pada dasarnya terdapat 2 jenis data utama yang digunakan dalam SIG, antara lain:

1. Data spasial

Data Spasial merupakan gambaran nyata suatu wilayah yang terdapat di permukaan bumi. Umumnya direpresentasikan berupa grafik, peta, gambar dengan format digital dan disimpan dalam bentuk koordinat $\mathrm{x}, \mathrm{y}$ (vektor) atau dalam bentuk image (raster) yang memiliki nilai tertentu.

Contoh: Data batas administrasi wilayah, data sebaran fasilitas umum, data ketinggian tempat dsb.

\section{Data Non Spasial}

Data Non Spasial atau sering disebut sebagai atribut adalah data berbentuk tabel dimana tabel tersebut berisi informasi-informasi yang dimiliki oleh obyek dalam data spasial. Data tersebut berbentuk data tabular yang saling terintegrasi dengan data spasial yang ada.

Contoh: nama desa atau kecamatan, jumlah penduduk dsb.

Sedangkan secara fundamental, SIG bekerja dengan 2 tipe model data geografis, yaitu:

1. Model Data Vektor

Dalam model data vektor, informasi posisi point, garis, dan polygon disimpan dalam bentuk koordinat $\mathrm{x}, \mathrm{y}$. Bentuk garis, seperti jalan dan sungai dideskripsikan sebagai kumpulan daru koordinat-koordinat point. Bentuk polygon, seperti daerah penjualan disimpan sebagai pengulangan koordinat yang tertutup.

\section{Model Data Raster}

Data raster terdiri dari sekumpulan grid atau sel seperti peta hasil scanning maupun gambar atau image. Masing-masing grid memiliki nilai tertentu yang bergantung pada bagaimana image tersebut digambarkan.

\section{d. Manusia}

Komponen manusia dalam SIG adalah sebagai pengguna (user), yaitu pelaksana yang bertanggungjawab dalam proses

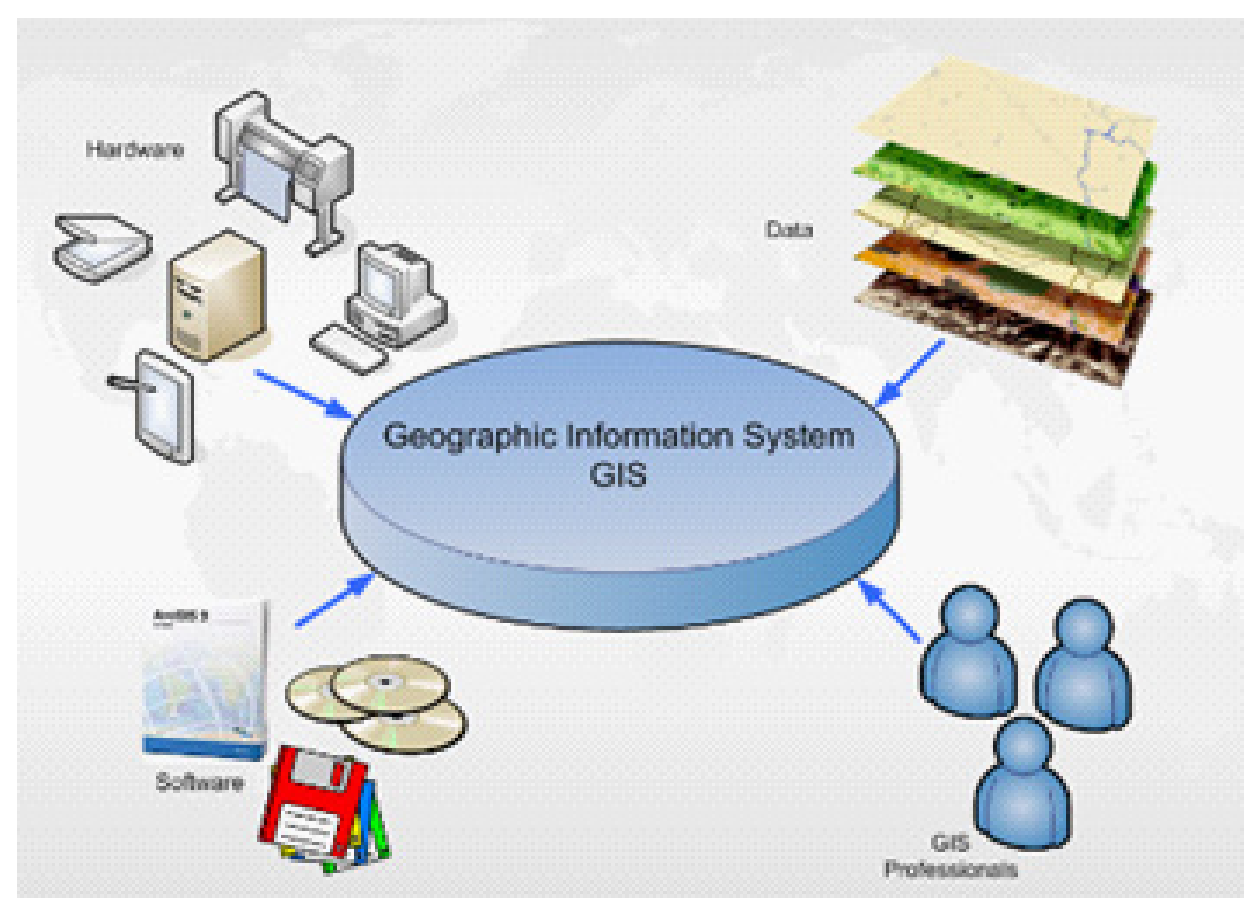

Gambar 2 Komponen SIG

(sumber: http://faculty.ksu.edu.sa) 
Etika Emaliyawati: Manajemen Mitigasi Bencana dengan Teknologi Informasi

pengumpulan, proses, analisis, dan publikasi data geografis. Komponen manusia merupakan inti elemen dari SIG karena manusia selain berperan sebagai pengguna juga merupakan perencana dari SIG. Pengguna SIG mempunyai tingkatan seperti pada sistem informasi lainnya, dari tingkat spesialis teknis yang mendesain dan mengelola sistem sampai pada pengguna yang menggunakan SIG untuk membantu pekerjaannya sehari-hari.

e. Metode

SIG yang baik memiliki keserasian antara rencana desain yang baik dan aturan dunia nyata, dimana metode, model dan implementasi akan berbeda untuk setiap permasalahan.

Untuk membangun SIG berbasis web perangkat lunak yang umum digunakan adalah Mapserver dan PostgreSQL.

WebGIS yang dibuat merupakan sebuah website yang memiliki fungsi utama sebagai Geographic Information System (GIS) yaitu sebuah sarana penyampaian informasi suatu tempat dengan memanfaatkan sebuah peta, yang dapat membantu mempercepat pengambilan keputusan. User/pemakai dapat melihat informasi dan mencari tempat yang diinginkannya. Aplikasi yang dibuat berfokus pada WebGIS Rumah Sakit/puskesmas di wilayah Ciamis, Jawa Barat. Web yang dibuat yaitu "Sistem Informasi Bencana Padjadjaran (SIMBARAN)".

\section{Hasil Penelitian}

Hasil penelitian telah terbentuk sistem informasi bencana bersisi elemen kesehatan yang dapat dilihat dalam bentuk tabel dan gambar disertai pembahasannya.

Diketahui dari tabel 1 potensi bencana terbesar di wilayah Kabupaten Ciamis adalah Longsor sebesar 29\%. Berdasarkan tabel 2 diketahui kemampuan layanan kesehatan dalam penanganan korban bencana di wilayah kabupaten Ciamis sebagian besar hanya mampu menangani korban bencana label hijau 84,21\%.. Penanggung jawab program

Tabel 1 Distribusi Frekuensi Potensi Bencana per Wilayah Puskesmas di Kabupaten Ciamis

\begin{tabular}{|c|c|c|}
\hline Jenis Bencana & Frekuensi & $\%$ \\
\hline Longsor & 29 & 29 \\
\hline Gempa & 22 & 22 \\
\hline Banjir & 12 & 12 \\
\hline Puting Beliung & 10 & 10 \\
\hline Wabah & 12 & 12 \\
\hline KLL & 15 & 15 \\
\hline
\end{tabular}

Tabel 2 Distribusi Frekuensi Tipe Layanan Kesehatan (label triage) di Kabupaten Ciamis

\begin{tabular}{lcc}
\hline \multicolumn{1}{c}{ Layanan Kesehatan } & Frekuensi & $\mathbf{\%}$ \\
\hline Merah & 1 & 2,63 \\
Kuning & 5 & 13,16 \\
Hijau & 32 & 84,21 \\
\hline
\end{tabular}

Tabel 3 Distribusi Frekuensi Sumber Daya Manusia (penanggung jawab) Program Bencana Di Kabupaten Ciamis

\begin{tabular}{lcc}
\hline \multicolumn{1}{c}{ Penanggung Jawab Program } & Frekuensi & $\mathbf{\%}$ \\
\hline Dokter & 2 & 5,40 \\
Perawat & 27 & 72,97 \\
Surveilans & 7 & 18,92 \\
Ka. TU & 1 & 2,7 \\
\hline
\end{tabular}


Etika Emaliyawati: Manajemen Mitigasi Bencana dengan Teknologi Informasi

Tabel 4 Distribusi frekuensi Sumber Daya Manusia (penanggung jawab) Program Bencana Tersertifikasi Di Kabupaten Ciamis

\begin{tabular}{lcc}
\hline Penanggung Jawab Program & Frekuensi & $\mathbf{\%}$ \\
\hline Tersertifikasi & 18 & 48,65 \\
Tidak Tersertifikasi & 19 & 51,35 \\
\hline
\end{tabular}
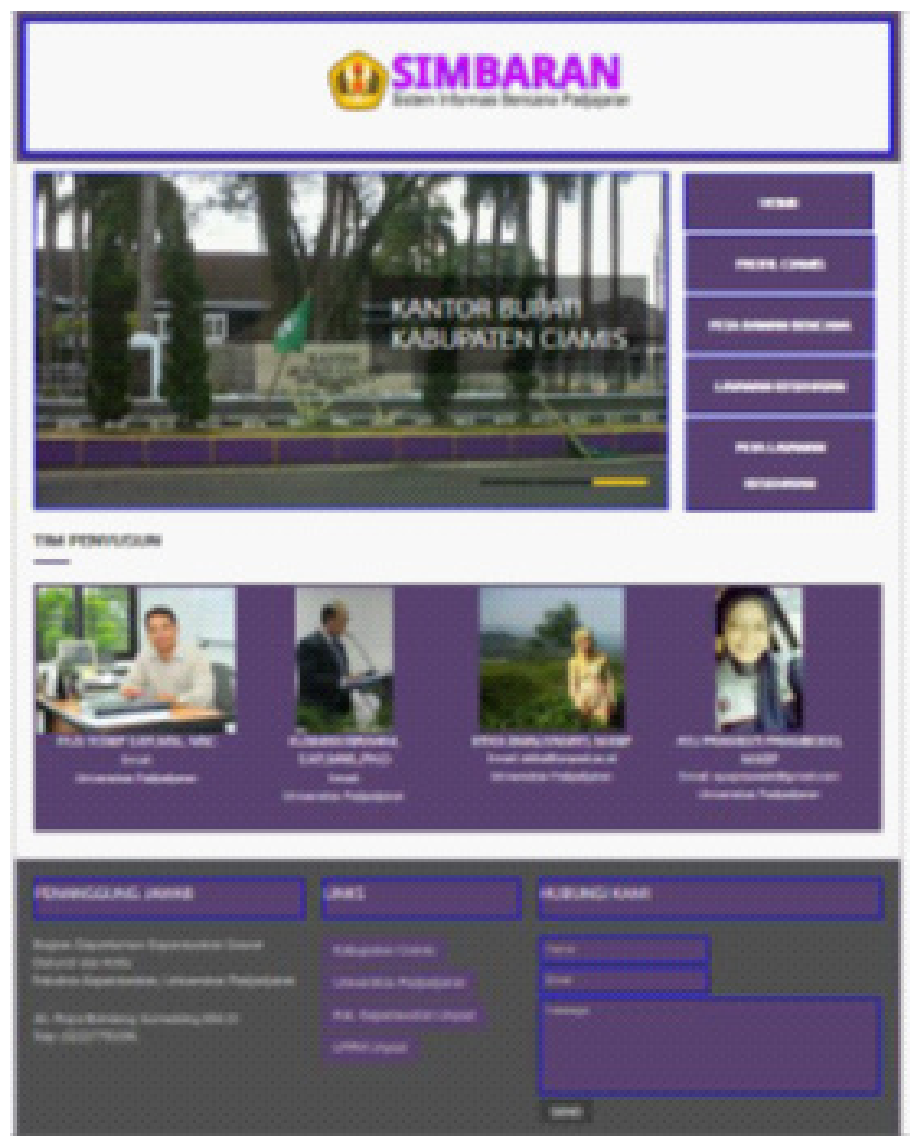

Gambar 3 Tampilan Pengguna Web Simbaran

bencana di masing-masing Puskesmas di kabupaten Ciamis terbanyak dipegang oleh perawat $72,97 \%$ (tabel 3). Berdasarkan tabel 4 diketahui penanggung jawab program bencana lebih dari setengahnya belum pernah mendapatkan pelatihan kebencanaan dan penanganan korban bencana.

Data-data tersebut termasuk didalamnya termasuk data koordinat tempat layanan kesehatan, jumlah ambulance, data logistik yang kemudian diolah dalam sistem informasi sehingga mudah dibaca dan disimpan dalam sistem informasi kesehatan yang dapat di akses melalui Sistem Informasi Bencana Padjadjaran "SIMBARAN" yang telah ter link dengan web Fakultas Keperawatan Universitas Padjadjaran, untuk tampilan web dapat dilihat sebagai berikut aplikasi SIG mitigasi bencana di kabupaten Ciamis.

Sebaran data layanan kesehatan dapat di lihat google map dengan tampilan warna sesuai dengan kemampuan penanganan korban seperti terlihat dalam gambar berikut ini

Pada menu ini ditampilkan PETA persebaran rumah sakit dan puskesmas di Kabupaten Ciamis. Titik-titik peta 
Etika Emaliyawati: Manajemen Mitigasi Bencana dengan Teknologi Informasi
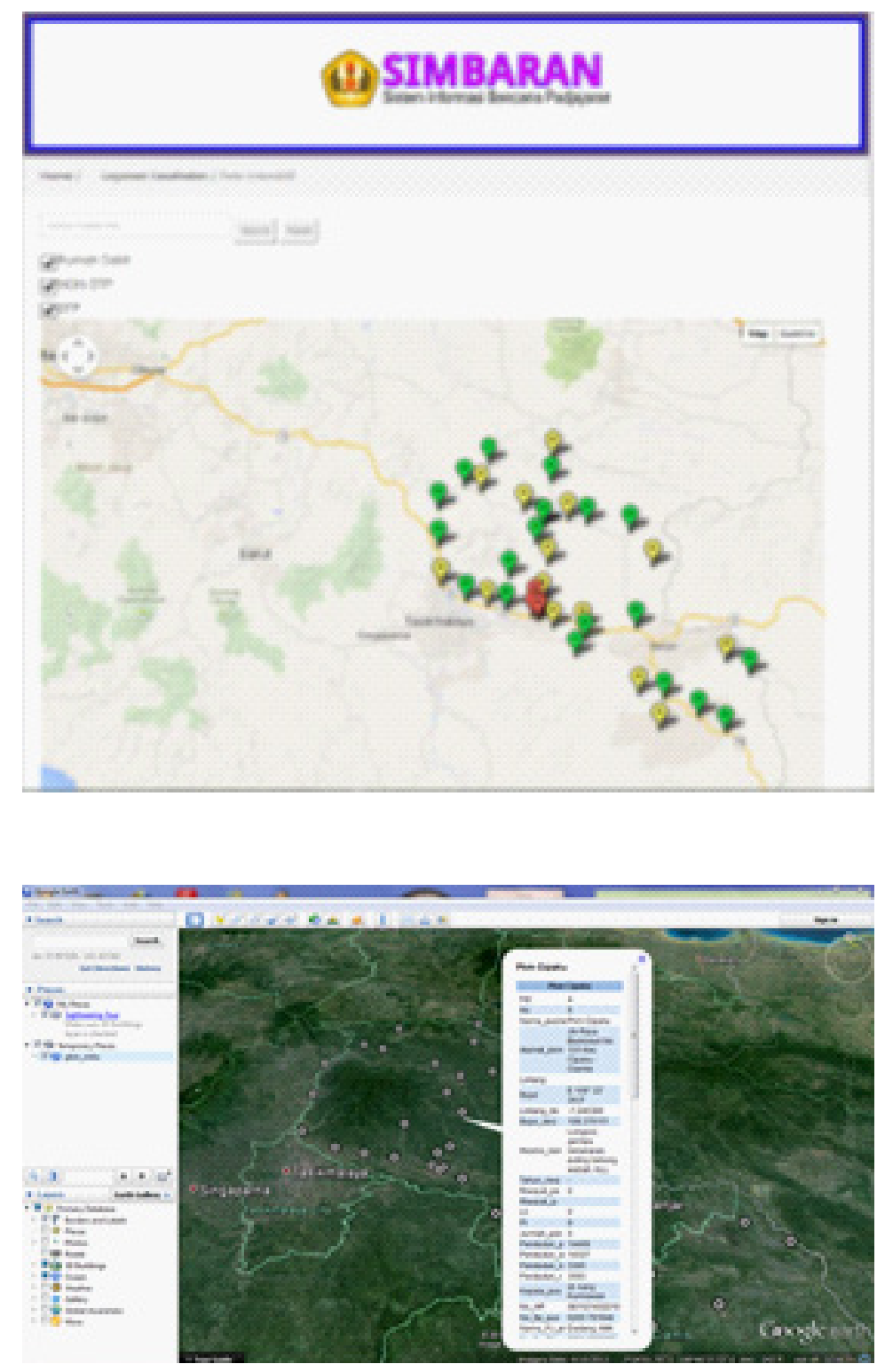

Gambar 4 Tampilan Sebaran Data Layanan Kesehatan

dibedakan warnanya berdasarkan jenis / tipe layanan kesehatan. Pada halaman ini juga disediakan fitur pencarian dan filtering untuk mempermudah pencarian rumah sakit dan puskesmas di Kabupaten Ciamis. Jika suatu titik layanan kesehatan diklik, maka akan ditampilkan detil informasi terkait rumah sakit / puskesmas tersebut. Detil informasi terdiri dari SDM, Fasilitas, ketersediaan alat kesehatan dan obat. Selain itu juga tersedia fasilitas pencarian arah di dalam peta ke lokasi tertentu dari titik rumah sakit /puskesmas. Data sumber daya manusia yang terdapat di layanan kesehatan dan yang lainnya dapat langsung terlihat di web, hal ini akan sangat memudahkan dalam pemberian informasi kepada para pengambil keputusan dalam hal ini BPBD dan Dinas Kesehatan kabupaten Ciamis pada saat kondisi bencana. Karena dilengkapi dengan sistem SIG maka SIMBARAN ini juga dilengkapi dengan sistem rujukan sehingga korban dapat 
Etika Emaliyawati: Manajemen Mitigasi Bencana dengan Teknologi Informasi

ditangani dengan tepat oleh orang yang tepat sehingga diharapkan dapat menurunkan tingkat kematian akibat bencana.

\section{Pembahasan}

Kabupaten Ciamis sebagai salah satu kabupaten di Jawa Barat menduduki urutan ke 5 sebagai kabupaten yang memiliki resiko rawan bencana setelah Kabupaten Garut, Bogor, Sukabumi, dan Cianjur. Resiko bencana yang paling tinggi adalah potensi gerakan tanah tinggi yang dapat disertai banjir bandang (http://www.bnpb.go.id). Hal ini sesuai dengan potensi bencana yang ada di Kabupaten Ciamis tertinggi diduduki oleh potensi bencana longsor $29 \%$, diikuti oleh gempa $22 \%$, dan kecelakaan lalu lintas $15 \%$ selain 3 terbesar potensi bencana di kabupaten Ciamis masih ada potensi bencana lain seperti puting beliung, banjir dan bencana wabah yang tidak kurang bahayanya dan memerlukan penanganan yang terpadu. Sesuai yang diungkapkan oleh Sadisun (2008) bahwa perlu adanya pemahaman karakteristik bencana dari masing-masing wilayah agar upaya mitigasi dan penanganan tanggap darurat bencana dapat dilaksanakan secara optimal.

Hampir seluruh kecamatan di daerah kabupaten Ciamis memiliki potensi longsor dari 27 kecamatan 25 kecamatan memiliki resiko potensi terjadinya longsor. Kejadian bencana longsor di Kabupaten Ciamis sendiri pernah sampai dengan memakan korban 1 orang meninggal dan 3 orang luka-luka (kategori luka berat dan ringan). Kondisi pergerakan tanah menengah tinggi ini akan semakin beresiko dengan tingginya curah hujan di daerah tersebut. Kabupaten Ciamis sebagai daerah yang mempunyai tingkat kerawanan cukup tinggi terhadap kejadian bencana alam (tanah longsor/pergerakan tahan dan banjir) berdasarkan pemetaan secara global yang telah dikaji dalam revisi RT/RW No. 2 tahun 2012-2029. Namun demikian, penanganan bencana belum tertangani secara optimal ((BPBD, 2010). Saat ini pemetaan bencana di kabupaten ciamis sendiri telah ada di Badan Penanggulangan Bencana Daerah Kabupaten Ciamis, tetapi untuk resiko potensi bencana yang ada di tiap wilayah yang meliputi ruang lingkup daerah binaan puskesmas belum terpapar mengenai hal tersebut. Padahal tentunya dengan adanya potensi bencana maka berarti berisiko juga untuk adanya korban akibat hal tersebut dan sektor kesehatan belumlah tergarap untuk menangani hal tersebut, sistem yang masih sederhana, manual dan tidak mudah di akses baik oleh pemangku kebijakan maupun oleh masyarakat bila bencana tersebut terjadi.

Kondisi alam yang rentan terjadinya bencana tentu memiliki resiko banyaknya korban yang ditimbulkan akibat bencana. Menurut Haryadi et al. (2007) paling tidak terdapat empat faktor utama yang dapat menimbulkan bencana yang terjadi menimbulkan banyak korban serta kerugian besar, antara lain 1) Kurangnya pemahaman terhadap karakteristik bahaya (hazards); 2) Sikap atau perilaku yang mengakibatkan penurunan kualitas sumberdaya alam (vulnerability); 3) kurangnya informasi atau peringatan dini (early warning) yang menyebabkan ketidakpastian; dan 4) Ketidakberdayaan atau ketidakmampuan dalam menghadapi ancaman bahaya. Salah satu upaya yang dapat dilakukan dalam rangka mengurangi dampak bencana (mitigasi) adalah dengan melibatkan berbagai multi disiplin ilmu dalam penanganan bencana, perawat sebagai profesi kesehatan terbesar di Indonesia yang tersebar mulai dari perkotaan sampai dengan desa terpencil dapat berperan aktif dalam penanganan bencana. Hal ini sesuai dengan yang diungkapkan oleh Vogt dan Kulbok (2008) perawat komunitas sebagai agen terdekat dengan masyarakat dan yang paling berperan dalam penanganan bencana. Hal ini tentu perlu dan harus dikembangakan dengan melibatkan berbagai disiplin ilmu dan profesi keperawatan itu sendiri salah satunya dengan berperan aktif dalam Himpunan Perawat Gawat Darurat Bencana Indonesia (HIPGABI). Selama ini berbagai ikatan terkait kebencanaan telah ada tetapi aspek kesehatan belum banyak tersentuh seperti hasil seminar dalam Ikatan Ahli Bencana Indonesia menyebutkan bahwa teknologi yang berkembang dalam kebencanaan belum menyentuh aspek kemanusiaan sehingga SIMBARAN merupakan salah teknologi tepat 
Etika Emaliyawati: Manajemen Mitigasi Bencana dengan Teknologi Informasi

guna yang digunakan untuk meminimalkan dampak korban bencana untuk mengurangi angka morbiditas dan mortalitas.

Masalah kesehatan yang mungkin muncul dari bencana sangat tergantung dari jenis bencana yang terjadi, bila bencana longsor yang terjadi maka masalah kesehatan yang terjadi adalah kasus meninggal karena tertimbun reruntuhan dan kasus lukaluka serta Crush Injury. Kondisi bencana alam seperti puting beliung pun dapat menimbulkan korban baik karena luka-luka fisik (trauma) maupun secara psikologis karena stres psikologis, histeria. Bencana gempa untuk permasalahan yang muncul adalah sebagian besar kasus trauma, bahkan dapat muncul korban kebakaran karena kebakaran merupakan bencana sekunder pasca gempa. Untuk kasus trauma terbanyak multiple trauma terutama trauma tumpul, patah tulang dan perdarahan. Selain itu respiratory distres (gagal nafas) dan poisoning (keracunan). Kondisi bencana banjir masalah kesehatan yang mungkin adalah meninggal akibat tenggelam, hypothermia, trauma dan penyakit menular akibat water born disease, dan permasalahan pengungsi seperti penampungan, makanan, kesehatan, air bersih, penerangan/listrik dan lain-lain.

Lembaga pengelola layanan kesehatan terdekat dengan area bencana, sumber sarana dan prasarana layanan kesehatan terdekat dengan area bencana, sumber daya manusia layanan kesehatan dan kebutuhan logistik serta peralatan yang dibutuhkan sesuai karakteristik bencana di tiap daerah, hal ini sangat berhubungan erat. Bencana dan masalah kesehatan yang muncul di Kabupaten Ciamis adalah kondisi trauma seperti multiple trauma, patah tulang, korban meninggal, hypothermia, crush injury dan lain-lain. Kabupaten Ciamis memiliki 27 Kecamatan dengan instansi layanan kesehatan terdiri dari 1 Rumah Sakit Umum Daerah (RSUD) dan 37 Puskesmas yang tersebar di setiap kecamatan. Dari hasil penelitian didapatkan bahwa kemampuan layanan kesehatan di Kabupaten Ciamis hanya RSUD (1\%) yang mampu menangani kasus-kasus kondisi gawat darurat (merah), sedangkan seluruh puskesmas tidak mempunyai fasilitasfasilitas penanganan untuk korban kondisi gawat darurat (99\%).

Untuk penanggungjawab program bencana sebagian besar dipegang oleh perawat $(72,97 \%)$, surveilans $(18,92 \%)$, Ka.TU $(2,7 \%)$ dan dokter $(5,4 \%)$. Sedangkan untuk penanganan kasus gawat darurat dibutuhkan kompetensi dan kemampuan dalam menangani kasus-kasus gawat darurat padahal dari hasil penelitian didapatkan bahwa lebih dari setengah (51,35\%) penanggung jawab program bencana tidak tersertifikasi untuk menangani kasus-kasus gawat darurat.

Ketika layanan kesehatan dimana di wilayahya memiliki potensi bencana sudah seharusnya fasilitas, sarana, dan prasarana dilengkapi alat-alat emergency dan penanggung jawab program serta tenaga kesehatan lainnya memiliki kompetensi dan kemampuan yang memadai untuk penanganan kasus-kasus gawat darurat. Bahkan tidak seluruh puskesmas yang ada di Kabupaten Ciamis memiliki fasilitas ambulance. Saranaprasarana kit emergency seperti collar neck, spalk, oropharingeal bahkan tidak ada di mayoritas layanan kesehatan puskesmas. Padahal ketika bencana terjadi, Puskesmas sebagai layanan kesehatan primer akan dituju masyarakat untuk menangani kasuskasus gawat darurat baik karena kecelakaan maupun dikarenakan oleh bencana sedangkan fasilitas tidak memadai maka hal ini akan menjadikan penanganan korban menjadi lebih lama. Penanganan korban yang tidak segera dilakukan dapat menimbulkan berbagai masalah seperti meningkatnya resiko kecacatan, komplikasi bahkan resiko kematian.

Adanya SIMBARAN ini diharapkan penanganan korban menjadi lebih cepat, terkoordinasidenganbaik.UntukSIMBARAN sendiri berisi fitur profil, peta rawan bencana, layanan kesehatan, peta layanan kesehatan yang berada wilayah kabupaten Ciamis. Untuk profil berisi prakata, deskripsi wilayah kabupaten Ciamis, Peta wilayah kabupaten ciamis, dan resiko bencana di Kabupaten Ciamis. Untuk tampilan peta rawan bencana menampilkan peta rawan bencana banjir, peta rawan bencana gempa, peta rawan bencana pergerakan tanah, peta potensi rawan tsunami. Untuk layanan kesehatan meliputi 1 Rumah 
Etika Emaliyawati: Manajemen Mitigasi Bencana dengan Teknologi Informasi

Sakit Umum Daerah dan 37 Pusat Kesehatan Masyarakat (Puskesmas). Dalam fitur layanan kesehatan terdapat data sumber daya manusia di bidang kesehatan meliputi dr spesialis, $\mathrm{dr}$ umum, jumlah perawat, dan tenaga yang tersertifikasi untuk penanganan kasus-kasus gawat darurat dan kritis. Fasilitas layanan kesehatan memuat data Bed Occupational Rate (BOR). Alat kesehatan dan obat-obatan emergency, peta lokasi dan label triage untuk kemampuan fasilitas layanan kesehatan dalam menangani kasus-kasus gawat darurat.

\section{Simpulan}

Sistem informasi bencana terkait aspek kesehatan telah tersedia dengan nama Sistem Informasi Bencana Padjadjaran "SIMBARAN" yang menggunakan sistem informasi geopraphic yang di dalamnya berisi kontent informasi kesehatan untuk penanganan kondisi bencana. Informasi ini dapat digunakan sebagai informasi dasar untuk mengambil keputusan dalam manajemen penanganan bencana, terutama berkaitan dengan sistem rujukkan. Data yang ada di dalam sistem sudah memadai dalam menghadapi kondisi bencana terutama pada fase akut. Sistem Informasi Bencana Padjadjaran "SIMBARAN" ini tidak dapat berdiri sendiri harus dikembangkan dengan bekerjasama bersama-sama dengan Badan Nasional Penanggulangan Bencana (BNPB), Badan Penanggulangan Bencana Daerah (BPBD), Badan Koordinasi Survey dan Pemetaan Nasional (BAKOSURTANAL) dan Lembaga Penerbangan dan Antariksa Nasional (LAPAN).

Direkomendasikan agar setiap kabupaten di wilayah Jawa Barat memiliki Sistem Informasi Bencana karena wilayah Jawa Barat yang rentan terhadap kejadian bencana.

\section{Daftar Pustaka}

Badan Penanggulangan Nasional Bencana, (2011). Peraturan Kepala Badan Nasional Penanggulangan Bencana Nomor 8 tahun 2011 tentang Standarisasi Data

\section{Kebencanaan}

Badan Penanggulangan Bencana Daerah, (2010-2015). Rencana Penanggulangan Bencana Daerah Kabupaten Ciamis.

Bernhardsen, T. (2002). Gerograhic Information Systems: An Introduction. (3rd Edition). John Wiley \& Sons Ltd. Canada.

Cholid, S. (2009). Sistem Informasi Geografis: Suatu Pengantar. Staf Akademik Departemen Ilmu Kesejahteraan Sosial FISIP UI. Bogor.

Haryadi, P., Ratag, M. A., Karnawati, D., Rizal, S., Surono, \& Sutardi. (2007). Pengenalan karakteristik bencana dan upaya mitigasinya di Indonesia. Dalam Triutomo, S., Widjaya, W., \& Amri, M. R. (Eds.).

Murni, T. W. (2010). Natural Disaster (Bencana Alam).S2 Program Studi Keperawatan Universitas Padjadjaran.

Sadisun, I. A. (2008). Pemahaman Karakteristik Bencana : Aspek Fundamental dalam Upaya Mitigasi dan Penanganan Tanggap Darurat Bencana Journal, 1-11. Retrieved from http://www.sadisun.enggeol. org/pdf/2008 Paper Gladian Panji Bencana.pdf.

PPNI.(2012). Peran Perawat dalam Bencana. Retrieved 30/7/2012, 2012, from http:// ppnikabpekalongan.blogspot.com/2012/01/ peran-perawat-dalam-penanganan-bencana. html.

Putra, A., Petpichetchian, W., \& Maneewat, K. (2011). Review: Public Health Nurses' Roles and Competencies in Disaster Management. Nurse Media Journal of Nursing, 1(1), 1-14. UNFPA. (2010). Guidelines on Data Issues in Humanitarian Crisis Situations.

Vogt,\& Kulbok. (2008). Care of Client in Disaster Settings Community Health Nursing: Advocacy for Population Health (5 th ed., Vol. 2). New Jersey: Pearson Prentice Hall. 